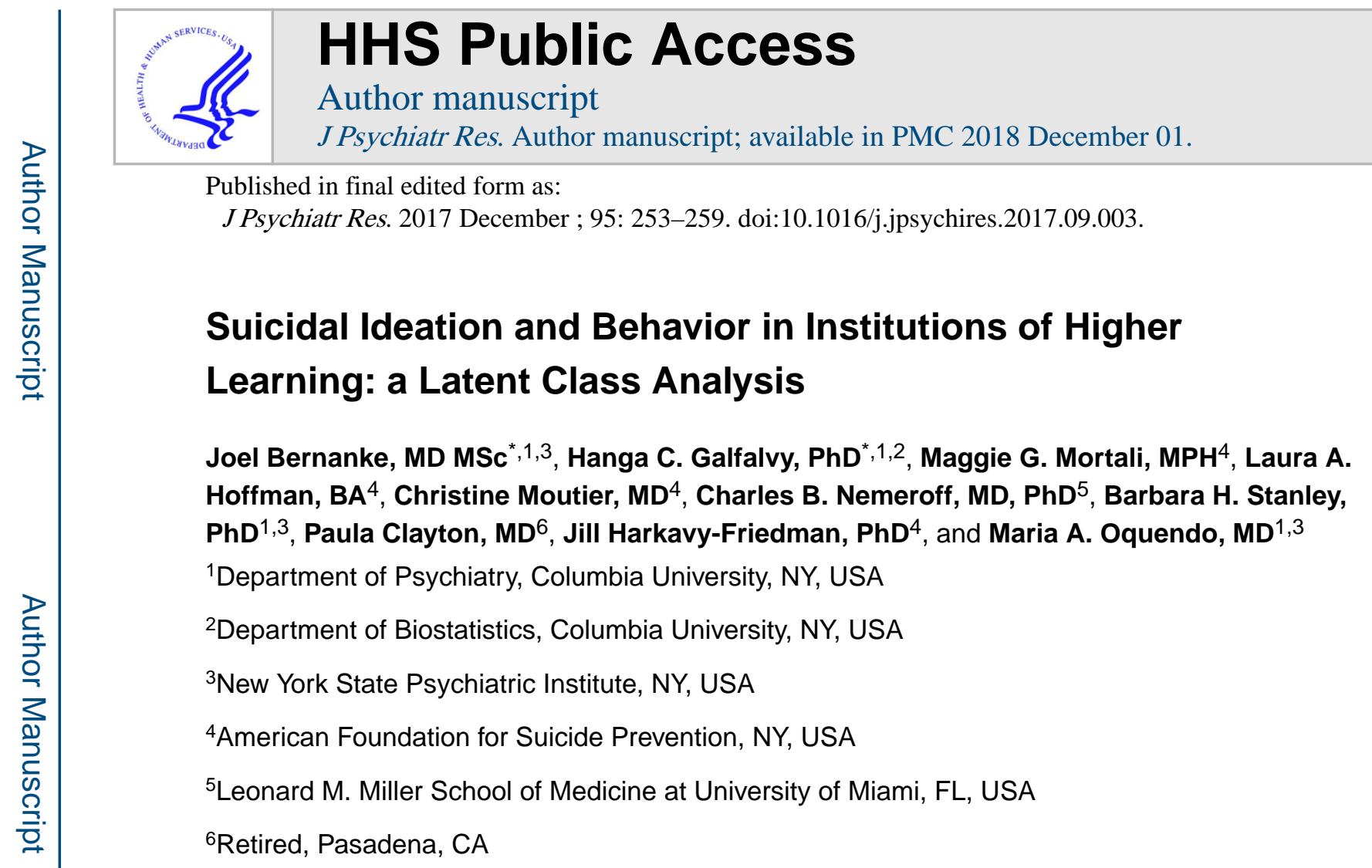

\begin{abstract}
Suicide is the second leading cause of death among undergraduate students, with an annual rate of 7.5 per 100,000. Suicidal behavior (SB) is complex and heterogeneous, which might be explained by there being multiple etiologies of SB. Data-driven identification of distinct at-risk subgroups
\end{abstract}

Corresponding Author: Hanga Galfalvy, PhD, Departments of Psychiatry and Biostatistics, Columbia University, Mailing Address: 1051 Riverside Dr, Unit 48, New York, NY 10032, Phone: 646-774-5460, Fax\# 646-774-7941, hcg2002@ columbia.edu.

these authors contributed equally to the manuscript.

Publisher's Disclaimer: This is a PDF file of an unedited manuscript that has been accepted for publication. As a service to our customers we are providing this early version of the manuscript. The manuscript will undergo copyediting, typesetting, and review of the resulting proof before it is published in its final citable form. Please note that during the production process errors may be discovered which could affect the content, and all legal disclaimers that apply to the journal pertain.

Financial disclosures

Dr. Bernanke reports no financial relationships with commercial interests.

Dr. Galfalvy's family owns stock in Illumina, Inc. She received funding from the American Foundation for Suicide Prevention related to the presented study.

Ms. Mortali, Ms. Hoffman and Dr. Harkavy-Friedman are full-time AFSP employees, with no financial relationships with commercial interests.

Dr. Moutier is a full-time AFSP employee. She chaired an Advisory Board at Allergan Pharmaceutical related to rapastinel and was speaker at Otsuka for a CME event.

Dr. Nemeroff has consulted in the last three years with Xhale, Takeda, Taisho Pharmaceutical Inc., Prismic Pharmaceuticals, Bracket (Clintara), Total Pain Solutions (TPS), Gerson Lehrman Group (GLG) Healthcare \& Biomedical Council, Fortress Biotech, Sunovion Pharmaceuticals Inc., Sumitomo Dainippon Pharma, Janssen Research \& Development LLC, Magstim, Inc. He is a stockholder of Xhale, Celgene, Seattle Genetics, Abbvie, OPKO Health, Inc., Bracket Intermediate Holding Corp., Network Life Sciences Inc., Antares. He is on the Scientific Advisory Boards for: American Foundation for Suicide Prevention (AFSP), Brain and Behavior Research Foundation (BBRF) (formerly named National Alliance for Research on Schizophrenia and Depression [NARSAD]), Xhale, Anxiety Disorders Association of America (ADAA), Skyland Trail, Bracket (Clintara), RiverMend Health LLC, Laureate Institute for Brain Research, Inc. He is on the Board of Directors for AFSP, Gratitude America, ADAA. He holds the following patents: Method and devices for transdermal delivery of lithium (US 6,375,990B1) Method of assessing antidepressant drug therapy via transport inhibition of monoamine neurotransmitters by ex vivo assay (US 7,148,027B2).

Dr. Stanley receives royalties for the commercial use of the Columbia Suicide Severity Rating Scale.

Dr. Clayton reports no financial relationships with commercial interests.

Dr. Oquendo receives royalties for the commercial use of the Columbia Suicide Severity Rating Scale. Her family owns stock in Bristol Myers Squibb. 
among undergraduates would bolster this argument. We conducted a latent class analysis (LCA) on survey data from a large convenience sample of undergraduates to identify subgroups, and validated the resulting latent class model on a sample of graduate students. Data were collected through the Interactive Screening Program deployed by the American Foundation for Suicide Prevention. LCA identified 6 subgroups from the undergraduate sample ( $\mathrm{N}=5654)$. In the group with the most students reporting current suicidal thoughts ( $\mathrm{N}=623,66 \%$ suicidal), $22.5 \%$ reported a prior suicide attempt, and $97.6 \%$ endorsed moderately severe or worse depressive symptoms. Notably, LCA identified a second at-risk group ( $\mathrm{N}=662,27 \%$ suicidal), in which only $1.5 \%$ of respondents noted moderately severe or worse depressive symptoms. When graduate students $(\mathrm{N}=1138)$ were classified using the model, a similar frequency distribution of groups was found. Finding multiple replicable groups at-risk for suicidal behavior, each with a distinct prevalence of risk factors, including a group of students who would not be classified as high risk with depression-based screening, is consistent with previous studies that identified multiple potential etiologies of SB.

\section{Keywords (MeSH)}

suicide; suicidal ideation; depression; adolescent behavior

\section{Introduction}

Suicide is the second leading cause of death for college students, with an estimated overall annual suicide rate of 7.5 per 100,000 (Drum et al., 2009; Silverman et al., 1997). The highest suicide rates are among students over age 25 and those enrolled in graduate school (Silverman et al., 1997). Factors associated with increased risk for suicidal behavior among young people include history of suicide attempt, depression, and substance use (D'Eramo et al., 2004; Dvorak et al., 2013; Esposito-Smythers and Spirito, 2004; Fowler et al., 1986; Garlow, 2002; Gonzalez, 2012; Nemeroff et al., 2001). Other risk factors include adverse life events, contact with legal authorities, family history of mental illness, family history of suicide, and history of sexual abuse (Agerbo et al., 2002; Cooper et al., 2002; Gray et al., 2002; Juon and Ensminger, 1997).

Mood, anxiety, and substance use disorders commonly emerge during late adolescence and early adulthood (Kessler et al., 2005). Among college students, the difficulties of age-related transitions are further exacerbated by social, academic, and professional stressors (Ross et al., 1999). A 2015 survey found that one in three college students reported "feeling so depressed that it was difficult to function," and one in 10 said they had "seriously considered attempting suicide" in the last 12 months (American College Health Association, 2015). Alarmingly, results from a screening project at one university found that only $14.5 \%$ of moderately severe or severely depressed students were receiving mental health treatment (Garlow et al., 2008).

The American Foundation for Suicide Prevention (AFSP) developed the Interactive Screening Program (ISP) to support institutions of higher learning in engaging at-risk students in mental healthcare. Implemented by each school's counseling center, the ISP 
provides screening, personalized feedback, and recommendations for next steps entirely online. The program offers students concerned about stigma and confidentially—common barriers to accessing services-an anonymous way to obtain information and support (Haas et al., 2008).

Latent class analysis (LCA), related to cluster analysis, can be used to discover groups of similar cases in multivariate categorical data. In the suicide risk literature, LCA has been used to identify precipitants for suicidal thoughts among adolescents of various ethnic and racial backgrounds (De Luca et al., 2014; Stoep et al., 2009); to predict suicidal behavior (Thompson et al., 2009); to recognize patterns in known risk factors for suicide among suicide decedents (Judd et al., 2012; Kim et al., 2003; Logan et al., 2011); to identify psychiatric disorder subtypes that might be more strongly associated with suicidal thoughts or behaviors ( $\mathrm{Li}$ et al., 2014; Pan et al., 2014); and to explore interactions among suicide risk factors (Pena et al., 2012).

We used LCA to identify subgroups of at-risk students using data collected via the ISP. Since suicidal behavior is complex and heterogeneous, there are likely multiple subtypes of suicidal behavior, and risk factors can differ across subtypes (Conner et al., 2007; Dombrovski et al., 2013; Mann et al., 2009). Data-driven identification of distinct at-risk groups in this sample would further bolster this argument. Characterization of these groups might propel a deeper understanding of suicidal behavior subtypes and their respective etiologies.

\section{Methods}

\section{Data collection and measures}

The ISP was implemented at a diverse set of United States institutions of higher learning over a 12-year period (2002-2014). The 45 schools varied in size (ranging from approximately 900 to 65,000 students), were from all major geographic regions, varied by urban or rural location, and educational environment. Each institution selected which students to invite to the ISP. Emails were sent from designated officials in batches at each school to the selected students' school email addresses. The emails linked to school-specific ISP websites where students could register using a self-assigned user ID and password. Once registered, access was provided to the online Stress and Depression Questionnaire (SDQ). All students completing the survey were invited to "dialogue" with a counselor on the website.

There were three versions of the core SDQ corresponding to the three waves of data collection (2002-2005; 2006-2011; and 2011-2013), with later versions including more detailed questions about suicidality and treatment. Wave 1 only included two institutions, and response options on the questions were worded differently from subsequent waves. Eighteen demographic questions were provided to every site; schools chose 5-8 to include with the SDQ. The core SDQ in wave 3 was composed of 36 questions covering: stressrelated behaviors (e.g. fights), intense emotional states (e.g. rage, feeling out of control), substance use, eating disorder symptoms, depressive symptoms using the PHQ-9, self-harm, suicidality (e.g. recent thoughts of suicide, history of suicide attempt), and treatment (e.g. on 
medication, in therapy) (Garlow et al., 2008; Kroenke et al., 2001; Spitzer et al., 1999; Spitzer et al., 2000). Most questions used a 4-point Likert scale (ranging from "not at all" to "most of the time"), some asked for a "yes/no" answer. The survey and data collection process were reviewed by the New York State Psychiatric Institute Institutional Review Board (IRB) and deemed not to require IRB approval.

\section{Data preparation and statistical analyses}

Data collected through the ISP were stored on each institution's ISP server. The data were then downloaded by the AFSP and prepared for analysis. The complete ISP data set included 9,535 entries (1,522 entries from wave 1; 3,197 from wave 2; 4,816 from wave 3). Analyses were performed using the statistical software R, version 2.12.1 (Team, 2008). To take advantage of the additional questions included in in waves 2 and 3, and the consistency of the response options in these waves, we excluded the data from wave 1 and combined waves 2 and 3. Subjects filling out the survey more than once were excluded. Additionally, subjects identifying as non-students (e.g. medical residents), or who did not identify their position at their school (e.g. undergraduate student), were excluded. These steps resulted in 6,792 unique entries (5,654 undergraduate students; 1,138 graduate and professional students) from 40 schools.

Descriptive statistics for the undergraduate and graduate students were calculated. Throughout the analysis, mixed effect models were applied with school as a random effect to adjust for differences between institutions. Mixed models with age as a fixed effect were used to compare the undergraduate and graduate samples. Mixed logistic models were used to test the association between recent suicidal ideation and answers to other survey questions. The False Discovery Rate was controlled using the Benjamini-Hochberg adjustment.

In preparation for performing LCA, school identity and measures with more than $30 \%$ missing values were removed. For interpretability, most questionnaire items on a 4-point Likert scale were dichotomized into two categories: "never" and "some of the time" versus "a lot of the time" and "most of the time." Items measuring suicidal or self-injurious thoughts were dichotomized into absent ("never") versus present (all other responses). Age was grouped into 3 categories ( $22,23-29,230$ ) and total PHQ-9 score into 4 categories (none $=0$, minimal $/$ mild $=1-9$, moderate $=10-14$, moderately severe $/$ severe $=15-27$ ). Any remaining missing values were coded into a separate category, instead of imputed, because their distribution was considered informative. Thirty-three variables were used in the LCA.

Latent class models with 3 through 10 classes were generated from the undergraduate data. Models were excluded if a class contained 5\% (283) or less of the sample. Bayes Information Criterion (BIC) was used to select the optimal model. In the selected model, classes were categorized from very low to high risk according to the proportion of respondents endorsing thoughts of suicide in the past 2 weeks. Descriptive statistics were generated by class in the selected model. Mixed models with class as fixed effect were used to compare proportions of certain characteristics across classes. Significance levels for 
comparison of pairs of adjacently ranked classes were adjusted using Bonferroni correction $(\mathrm{k}=5)$.

The PHQ-9 was used preferentially to characterize depression in the sample; the PHQ-8 was used when modeling the relationship between depressive symptoms and suicidal ideation. To illustrate the relationship between depression and suicidal ideation, especially the departures of class-level aggregate measures from an expected logistic relationship between the two, we prepared a figure of average PHQ- 8 score by proportion of respondents with thoughts of suicide in each cluster. The expected proportion was generated from mixed logistic modeling using the entire undergraduate sample, with PHQ8 as a fixed effect. Scores of 10 or more on the PHQ-8 were considered "depression" (Kroenke et al., 2009). For validation of the cluster structure, the selected latent class model was used to predict the class membership of the graduate students. Mixed logistic models with and without class as a predictor of undergraduate/graduate student status were compared using a chi-square test to determine if the distribution of classes varied between the undergraduate and graduate student samples.

\section{Results}

The median age was 20 for undergraduate and 26 for graduate students. Respondents identifying as women comprised the majority of both samples. The prevalence of moderately severe or severe depression was $23.7 \%$ in undergraduate and $15.0 \%$ in graduate students; $14.3 \%$ and $10.0 \%$ endorsed recent thoughts of suicide, with $7.1 \%$ and $4.9 \%$ indicating they had made at least one prior suicide attempt, respectively. Accounting for age and clustering by school, there were no statistically significant differences between the two samples (Table $1)$.

In the undergraduate sample, recent thoughts of suicide were associated with depression severity, as measured by PHQ-8 score (for each SD increase in PHQ-8 score OR=2.89, 95\% CI: 2.64-3.17, $\mathrm{p}<0.0001)$. Recent thoughts of suicide were also associated with the individual PHQ8 items and with all the other variables used in the LCA, even after adjustment for multiple testing, with the exception of whether or not the student provided an email address (Supplement Table 1). Thoughts of being better off dead or suicide (the last question on the PHQ-9) was the item most strongly associated with thoughts of suicide (OR=62.4, 95\% CI: 47.8-81.5, adjusted $\mathrm{p}<0.0001)$. Other associations included feeling hopeless ( $\mathrm{OR}=7.8,95 \%$ CI: 6.6-9.2, $\mathrm{p}<0.0001)$, feeling like a failure ( $\mathrm{OR}=6.3,95 \%$ CI: $5.3-$ 7.6, $\mathrm{p}<0.0001)$, feeling desperate $(\mathrm{OR}=6.0,95 \%$ CI: 5.1-7.1, $\mathrm{p}<0.0001)$, feeling life is difficult (OR=5.3, 95\% CI: 3.8-7.4, $\mathrm{p}<0.0001)$, and feeling intensely lonely $(\mathrm{OR}=5.0,95 \%$ CI: $4.2-5.9, \mathrm{p}<0.0001)$.

In the LCA, the 6 class model had the lowest BIC, subject to our condition on minimum group size (BIC=170,709, $\mathrm{G}^{2}=7,433, \mathrm{df}=5,241$; Supplement Figure 1), and was selected for further analysis. The proportion of respondents endorsing recent thoughts of suicide ranged from $0.7 \%$ to $66 \%$ across the classes, which were ordered from 1 (very low risk) to 6 (high risk). The 6 classes are further described in Table 2. Though the prevalence of most suicide risk factors increased with the prevalence of recent thoughts of suicide, Figure 1 illustrates 
that this ordering did not hold true for all risk factors. For example, a smaller proportion of respondents in class 5 endorsed moderately severe or severe depression, or a previous suicide attempt, than in class 4.

In class 1 , categorized as very low risk, $0.7 \%$ of respondents had thoughts of suicide in the past 2 weeks, and $1.5 \%$ reported a prior suicide attempt (Table 3). Respondents in this class were older (46.1\% were over 22) and identified as men (47.6\%). Though $33.8 \%$ of the members of this class indicated their life was stressful, many did not endorse any depressive symptoms and no members endorsed more than mild symptoms. Almost no members reported feeling hopeless, like a failure, desperate, or lonely a lot or most of the time.

In classes 2 and 3, categorized as low risk, 3.8\% of respondents in each class endorsed recent thoughts of suicide, and $4.1 \%$ and $5.2 \%$ reported a past suicide attempt. Most members of these classes endorsed feeling like their problems made their lives very or extremely difficult ( $85.2 \%$ of class 3 and $92.6 \%$ of class 4 ) and that they were nervous a lot or most of the time $(61.1 \%$ and $63.0 \%)$. Few members of either class identified as men ( $23.8 \%$ of both). The difference between these two classes was in their depressive symptoms: no members of class 2 scored above the mild range on the PHQ-9, while 97.8\% of class 3 scored in the moderate range, with most reporting difficulties with sleep (82\%), appetite, and concentration. Few members of either class noted feeling hopeless (3.6\% and $6.5 \%)$, though some members of both classes noted feeling intensely lonely (21.0\% and $30.4 \%)$.

In class 4, categorized as moderate risk, $15.5 \%$ of respondents endorsed thoughts of suicide, and $11.2 \%$ noted a past attempt. Compared to the lower risk classes, members of this class were more depressed, with $88.5 \%$ of respondents scoring in the moderately severe or severe range. Additionally, more members of this class endorsed feeling hopeless (48.6\%), like a failure (79.6\%), desperate (33.1\%), and lonely (61.6\%).

In class 5, categorized as moderate to high risk, $26.7 \%$ endorsed thoughts of suicide, significantly more than in class $4(\mathrm{z}=5.8, \mathrm{p}<0.0001)$, with $8.0 \%$ noting a past attempt (not significantly different from class $4, \mathrm{p}=0.2310)$. More members of class 5 indicated feeling hopeless $(67.2 \%)$, like a failure (65.1\%), desperate (45.6\%), and lonely (64.7\%) compared to class 4 . However, only $1.5 \%$ of members of this class scored their depressive symptoms in the moderately severe or severe range, significantly fewer than the $88.5 \%$ in class $4(\mathrm{z}=$ $-17.9, \mathrm{p}<0.0001)$. Though similar proportions of respondents in classes 4 and 5 reported sad mood (77.8\% and $71.6 \%$, respectively), fewer members of class 5 noted anhedonia or other neurovegetative symptoms (e.g. poor sleep, poor energy), which kept their total PHQ-9 scores down. Notably, more members of class 5 identified as men (43.2\%) than in the other classes, except class 1 , the very low risk class.

Finally, in class 6, which was categorized as high risk, 66.0\% endorsed thoughts of suicide, and $22.5 \%$ noted a prior attempt. On the PHQ-9, 90\% endorsed the suicide item. More members of this class noted moderately severe or severe depressive symptoms; were 22 or younger; noted difficulties with stress, fights, anxiety, desperation, loneliness, hopelessness; and reported drinking more alcohol than usual than any other class. Members of class 6 who 
did not endorse thoughts of suicide were less likely to report having attempted suicide compared to those who did (15\% versus $27 \%$ ). However, a similar proportion self-rated as moderately severely or severely depressed (97\% versus $99 \%$ ), indicated having arguments or fights in the past week (44\% versus $40 \%$ ), reported drinking more than usual (22\% and $21 \%$ ), and reported that their problems felt very or extremely difficult (99\% in both groups). Additionally, more respondents who did not endorse thoughts of suicide noted intense anxiety or panic ( $80 \%$ versus $68 \%$ ) and reported taking psychoactive drugs (24\% versus $19 \%)$.

Alcohol consumption varied across the six classes. Compared to class 1, the very low risk class, all five remaining classes had a significantly greater proportion of respondents endorsing drinking more than usual. Class 6 had the highest proportion $(\mathrm{OR}=13.1,95 \% \mathrm{CI}$ : 8.1-19.8, $\mathrm{p}<0.0001$ ), and classes 2 through 5 had intermediate proportions (ORs=3.9-5.5, $\mathrm{p}<0.0001)$. A similar pattern was observed in the proportion of respondents reporting that alcohol use was interfering with their schoolwork.

The relationship among depression score on the PHQ8, class membership, and recent thoughts of suicide is depicted in Figure 3. The average PHQ8 score in class 5 was below the cutoff for depression, yet the proportion of respondents endorsing suicide was higher than expected based on logistic modeling of the entire sample. The average PHQ8 scores in classes 3 and 4 were greater than the cutoff, yet fewer respondents endorsed recent suicidal thoughts than expected.

We applied the latent class model derived from the undergraduate data to the graduate student sample. Among the graduate students, we found a monotonic rise in the percentage of respondents reporting recent thoughts of suicide across the classes, ranging from $1.0 \%$ in class 1 to $62.1 \%$ in class 6 . Compared to the undergraduate sample, a larger proportion of the graduate students were in classes 1 (23\% versus $28 \%), 2$ (25\% versus $28 \%), 3(15 \%$ versus $16 \%$ ), and 5 (12\% and 14\%), and a smaller proportion were in 4 (14\% versus $9 \%$ ), and $6(11 \%$ versus $6 \%)$. However, these differences were not statistically significant $\left(\chi^{2}=6.19, \mathrm{df}=5, \mathrm{p}=0.2885\right)$, which suggests the latent suicide risk structure in the two populations is similar.

\section{Discussion}

In this study, we identified subgroups of at-risk undergraduate and graduate students using LCA. The prevalence of depression and thoughts of suicide in the undergraduate sample was similar to a previous AFSP screening survey deployed at a single institution, though a smaller percentage in this sample reported a previous suicide attempt (Garlow et al., 2008). Other studies have found similar rates of thoughts of suicide but lower rates of depression (Mackenzie et al., 2011). One large national survey estimated a lower burden of sad mood, hopelessness, and thoughts of suicide, though these differences could be explained by differing sampling and assessment methods (American College Health Association, 2015).

Like some previous LCAs of established and potential suicide risk factors among at-risk individuals or suicide decedents, the results of this study indicated that multi-class models 
had superior fit relative to two class models, and that the prevalence of established risk factors varied across classes (De Luca et al., 2014; Judd et al., 2012; Logan et al., 2011; Thompson et al., 2009). More specifically, this study's finding that members of one higher risk class (class 5) reported fewer depressive symptoms than a lower risk class (class 4) is consistent with two studies of suicide decedents that found at least one class without depressive symptoms, and with a prospective study where the high risk group had fewer depressed members than the medium risk group (Judd et al., 2012; Logan et al., 2011; Thompson et al., 2009). These results are in contrast to one large cohort study that identified only two latent classes, which they termed low versus high ideation, and a smaller study of suicide decedents that found depressive symptoms were distributed across all the latent classes, with childhood onset, co-morbidity, and substance misuse predicting class membership (Kim et al., 2003; Stoep et al., 2009).

We ordered the six classes based on the proportion of students with current suicidal thoughts. Current suicidal ideation is a significant predictor of future suicide attempts, as is past suicide attempt (Galfalvy et al., 2008). Our choice reflected a preference for using a factor that was more proximal in time and had a wider range of endorsement proportions among our classes.

Consistent with prior research on suicide risk factors, we observed correlations between thoughts of being better off dead or suicide and depression, stress, anxiety, hopelessness, and alcohol use (Esposito-Smythers and Spirito, 2004; Horwitz et al., 2016; Nemeroff et al., 2001; Nyer et al., 2013). In fact, the presence of this entire constellation of symptoms was sufficient for the latent class model to categorize respondents in the highest risk group (class 6), even if they did not endorse thoughts of suicide.

The model also identified a group of respondents (class 5) who endorsed suicidal thoughts but did not appear depressed. Though most members of class 5 endorsed sad mood, few endorsed neurovegetative symptoms, and virtually none had PHQ-9 scores in the moderately severe or severe range. Yet more respondents in this group endorsed feeling hopeless, desperate, and intensely lonely than in class 4 , which had a much greater percentage of respondents endorsing significant depression. This suggests an association between these symptoms and suicidal thoughts even in the absence of a depressive episode, consistent with previous work on the relationship between emotional dysregulation, distress, and suicide (Bowen et al., 2015).

LCA assumes the existence of a finite number of distinct at-risk subpopulations, rather than a single continuous latent suicide risk variable, or "risk continuum." If there were a risk continuum, we would expect LCA to identify ordered but arbitrary "slices" along it. Here, we have provided evidence that some classes, especially class 5, would break the order on reasonable definitions of a risk continuum, and instead should be viewed as samples from separate subtypes of subjects.

One way to conceptualize our findings is that there are at least two different types of individuals at risk for suicidal ideation (classes 4 and 6; and class 5). Some individuals (classes 4 and 6) clearly have depressive symptoms that may be driving suicidal thinking, 
while others (class 5) report being desperate, lonely and hopeless despite not being significantly depressed. It would be useful to examine whether depression motivates suicidal ideation and behavior in the first two groups and life events, leading to feelings of hopelessness and desperation, are at work in the latter (Oquendo et al., 2014). Other possible etiologies of suicidal thoughts in class 5 include demoralization or the wounded self-worth characteristic of narcissism (Coleman et al., 2017; Dohrenwend et al., 1980).

Unlike previous studies, the derived latent class model was applied to a second sample and the distributions of classes were compared. The result was a largely similar distribution of classes in the graduate sample. The general agreement between the distributions and risk profiles of classes between the undergraduate and graduate sample; the same monotonic rise in recent thoughts of suicide from classes 1 to 6 ; and the reduced frequency of depression in class 5 relative to class 4 in the graduate sample all contribute to the model's face validity. As a reminder, we found no differences between undergraduate and graduate students on univariate comparisons of factors used in the LCA, after adjusting for age. Clearly further assessment with prospective data would be required to establish its utility.

There are some limitations to the study. First, the colleges and universities had considerable latitude in selecting survey recipients, raising the possibility of selection bias. Though we controlled for campus-to-campus variability in our statistical analysis, and application of the latent class model to the graduate sample produced a similar result, it is unclear if the model would be robust to a different sampling method. Response bias could also affect the outcomes in either direction, by lowering or raising response rates in certain at-risk subpopulations compared to those in others, or by systematic bias in the responses of certain sub-populations. Third, though we applied the selected latent class model to a graduate student population, we did not use a second, independent undergraduate sample for validation.

In conclusion, LCA identified groups at-risk of suicide in a sample of college and graduate students, each with a distinct prevalence of risk factors, including a group of students who would not necessarily be classified as high risk with depression-based screening, but nevertheless appear high-risk on a number of measures. To our knowledge, this is the first study to validate a latent class model on a second data set. This data-driven approach to identifying high-risk groups is consistent with previous studies that identified multiple potential etiologies of suicidal behavior.

\section{Supplementary Material}

Refer to Web version on PubMed Central for supplementary material.

\section{Acknowledgments}

Funding: This work is funded by the American Foundation for Suicide Prevention and the National Institute of Mental Health (P50 MH090964, R01MH109326). 


\section{References}

Agerbo E, Nordentoft M, Mortensen PB. Familial, psychiatric, and socioeconomic risk factors for suicide in young people: nested case-control study. BMJ (Clinical research ed.). 2002; 325(7355): 74.

American College Health Association. National College Health Assessment II. Hanover, MD: 2015.

Bowen R, Balbuena L, Peters EM, Leuschen-Mewis C, Baetz M. The Relationship between Mood Instability and Suicidal Thoughts. Archives of suicide research : official journal of the International Academy for Suicide Research. 2015; 19(2):161-171. [PubMed: 25774548]

Coleman D, Lawrence R, Parekh A, Galfalvy H, Blasco-Fontecilla H, Brent DA, Mann JJ, BacaGarcia E, Oquendo MA. Narcissistic Personality Disorder and suicidal behavior in mood disorders. J Psychiatr Res. 2017; 85:24-28. [PubMed: 27816770]

Conner KR, Hesselbrock VM, Meldrum SC, Schuckit MA, Bucholz KK, Gamble SA, Wines JD, Kramer J. Transitions to, correlates of, suicidal ideation, plans, and unplanned and planned suicide attempts among 3,729 men and women with alcohol dependence. Journal of studies on alcohol and drugs. 2007; 68(5):654-662. [PubMed: 17690798]

Cooper J, Appleby L, Amos T. Life events preceding suicide by young people. Social psychiatry and psychiatric epidemiology. 2002; 37(6):271-275. [PubMed: 12111032]

D'Eramo KS, Prinstein MJ, Freeman J, Grapentine WL, Spirito A. Psychiatric diagnoses and comorbidity in relation to suicidal behavior among psychiatrically hospitalized adolescents. Child psychiatry and human development. 2004; 35(1):21-35. [PubMed: 15626323]

De Luca S, Yan Y, Lytle M, Brownson C. The associations of race/ethnicity and suicidal ideation among college students: a latent class analysis examining precipitating events and disclosure patterns. Suicide \& life-threatening behavior. 2014; 44(4):444-456. [PubMed: 24816248]

Dohrenwend BP, Shrout PE, Egri G, Mendelsohn FS. Nonspecific psychological distress and other dimensions of psychopathology. Measures for use in the general population. Arch Gen Psychiatry. 1980; 37(11):1229-1236. [PubMed: 7436685]

Dombrovski AY, Szanto K, Clark L, Reynolds CF, Siegle GJ. Reward signals, attempted suicide, and impulsivity in late-life depression. JAMA psychiatry. 2013; 70(10):1. [PubMed: 23925710]

Drum DJ, Brownson C, Denmark A, Smith SE. New data on the nature of suicidal crises in college students: Shifting the paradigm. Professional Psychology: Research and Practice. 2009; 40(3):213.

Dvorak RD, Lamis DA, Malone PS. Alcohol use, depressive symptoms, and impulsivity as risk factors for suicide proneness among college students. Journal of affective disorders. 2013; 149(1-3):326334. [PubMed: 23474093]

Esposito-Smythers C, Spirito A. Adolescent substance use and suicidal behavior: a review with implications for treatment research. Alcoholism, clinical and experimental research. 2004; $28(5$ Suppl)

Fowler RC, Rich CL, Young D. San Diego Suicide Study II. Substance abuse in young cases. Archives of general psychiatry. 1986; 43(10):962-965. [PubMed: 3753161]

Galfalvy HC, Oquendo MA, Mann JJ. Evaluation of clinical prognostic models for suicide attempts after a major depressive episode. Acta Psychiatr Scand. 2008; 117(4):244-252. [PubMed: 18321353]

Garlow SJ. Age, gender, and ethnicity differences in patterns of cocaine and ethanol use preceding suicide. The American journal of psychiatry. 2002; 159(4):615-619. [PubMed: 11925300]

Garlow SJ, Rosenberg J, Moore JD, Haas AP, Koestner B, Hendin H, Nemeroff CB. Depression, desperation, and suicidal ideation in college students: results from the American Foundation for Suicide Prevention College Screening Project at Emory University. Depression and anxiety. 2008; 25(6):482-488. [PubMed: 17559087]

Gonzalez VM. Association of solitary binge drinking and suicidal behavior among emerging adult college students. Psychology of Addictive Behaviors. 2012; 26(3):609. [PubMed: 22288976]

Gray D, Achilles J, Keller T, Tate D, Haggard L, Rolfs R, Cazier C, Workman J, McMahon WM. Utah youth suicide study, phase I: government agency contact before death. Journal of the American Academy of Child and Adolescent Psychiatry. 2002; 41(4):427-434. [PubMed: 11931599] 
Gvion Y, Apter A. Aggression, impulsivity, and suicide behavior: a review of the literature. Archives of suicide research : official journal of the International Academy for Suicide Research. 2011; 15(2): 93-112. [PubMed: 21541857]

Haas A, Koestner B, Rosenberg J, Moore D, Garlow SJ, Sedway J, Nicholas L, Hendin H, Mann JJ, Nemeroff CB. An interactive web-based method of outreach to college students at risk for suicide. Journal of American college health : J of ACH. 2008; 57(1):15-22.

Horwitz AG, Berona J, Czyz EK, Yeguez CE, King CA. Positive and Negative Expectations of Hopelessness as Longitudinal Predictors of Depression, Suicidal Ideation, and Suicidal Behavior in High-Risk Adolescents. Suicide Life Threat Behav. 2016

Judd F, Jackson H, Komiti A, Bell R, Fraser C. The profile of suicide: changing or changeable? Social psychiatry and psychiatric epidemiology. 2012; 47(1):1-9.

Juon HS, Ensminger ME. Childhood, adolescent, and young adult predictors of suicidal behaviors: a prospective study of African Americans. Journal of child psychology and psychiatry, and allied disciplines. 1997; 38(5):553-563.

Kessler RC, Berglund P, Demler O, Jin R, Merikangas KR, Walters EE. Lifetime prevalence and ageof-onset distributions of DSM-IV disorders in the National Comorbidity Survey Replication. Arch Gen Psychiatry. 2005; 62(6):593-602. [PubMed: 15939837]

Kim C, Lesage A, Seguin M, Chawky N, Vanier C, Lipp O, Turecki G. Patterns of co-morbidity in male suicide completers. Psychological medicine. 2003; 33(7):1299-1309. [PubMed: 14580083]

Kroenke K, Spitzer RL, Williams JB. The PHQ-9: validity of a brief depression severity measure. Journal of general internal medicine. 2001; 16(9):606-613. [PubMed: 11556941]

Kroenke K, Strine TW, Spitzer RL, Williams JB, Berry JT, Mokdad AH. The PHQ-8 as a measure of current depression in the general population. J Affect Disord. 2009; 114(1-3):163-173. [PubMed: 18752852]

Lewinsohn PM, Rohde P, Seeley JR, Baldwin CL. Gender differences in suicide attempts from adolescence to young adulthood. J Am Acad Child Adolesc Psychiatry. 2001; 40(4):427-434. [PubMed: 11314568]

Li Y, Aggen S, Shi S, Gao J, Li Y, Tao M, Zhang K, Wang X, Gao C, Yang L, Liu Y, Li K, Shi J, Wang G, Liu L, Zhang J, Du B, Jiang G, Shen J, Zhang Z, Liang W, Sun J, Hu J, Liu T, Wang X, Miao G, Meng H, Li Y, Hu C, Li Y, Huang G, Li G, Ha B, Deng H, Mei Q, Zhong H, Gao S, Sang H, Zhang Y, Fang X, Yu F, Yang D, Liu T, Chen Y, Hong X, Wu W, Chen G, Cai M, Song Y, Pan J, Dong J, Pan R, Zhang W, Shen Z, Liu Z, Gu D, Wang X, Liu X, Zhang Q, Flint J, Kendler KS. Subtypes of major depression: latent class analysis in depressed Han Chinese women. Psychological medicine. 2014; 44(15):3275-3288. [PubMed: 25065911]

Logan J, Hall J, Karch D. Suicide categories by patterns of known risk factors: a latent class analysis. Archives of general psychiatry. 2011; 68(9):935-941. [PubMed: 21893660]

Mackenzie S, Wiegel JR, Mundt M, Brown D, Saewyc E, Heiligenstein E, Harahan B, Fleming M. Depression and suicide ideation among students accessing campus health care. The American journal of orthopsychiatry. 2011; 81(1):101-107. [PubMed: 21219281]

Mann JJ, Arango VA, Avenevoli S, Brent DA, Champagne FA, Clayton P, Currier D, Dougherty DM, Haghighi F, Hodge SE, Kleinman J, Lehner T, McMahon F, Mościcki EK, Oquendo MA, Pandey GN, Pearson J, Stanley B, Terwilliger J, Wenzel A. Candidate endophenotypes for genetic studies of suicidal behavior. Biological psychiatry. 2009; 65(7):556-563. [PubMed: 19201395]

Nemeroff CB, Compton MT, Berger J. The depressed suicidal patient. Assessment and treatment. Annals of the New York Academy of Sciences. 2001; 932:1-23.

Nyer M, Holt DJ, Pedrelli P, Fava M, Ameral V, Cassiello CF, Nock MK, Ross M, Hutchinson D, Farabaugh A. Factors that distinguish college students with depressive symptoms with and without suicidal thoughts. Annals of clinical psychiatry : official journal of the American Academy of Clinical Psychiatrists. 2013; 25(1):41-49. [PubMed: 23376869]

Oquendo MA, Perez-Rodriguez MM, Poh E, Sullivan G, Burke AK, Sublette ME, Mann JJ, Galfalvy H. Life events: a complex role in the timing of suicidal behavior among depressed patients. Molecular psychiatry. 2014; 19(8):902-909. [PubMed: 24126928]

Pan PM, Salum GA, Gadelha A, Moriyama T, Cogo-Moreira H, Graeff-Martins AS, Rosario MC, Polanczyk GV, Brietzke E, Rohde LA, Stringaris A, Goodman R, Leibenluft E, Bressan RA. 
Manic symptoms in youth: dimensions, latent classes, and associations with parental psychopathology. Journal of the American Academy of Child and Adolescent Psychiatry. 2014; 53(6):625-63400. [PubMed: 24839881]

Pena JB, Matthieu MM, Zayas LH, Masyn KE, Caine ED. Co-occurring risk behaviors among White, Black, and Hispanic US high school adolescents with suicide attempts requiring medical attention, 1999-2007: implications for future prevention initiatives. Social psychiatry and psychiatric epidemiology. 2012; 47(1):29-42. [PubMed: 21153018]

Ross SE, Niebling BC, Heckert TM. Sources of stress among college students. Social psychology. 1999; 61(5):841-846.

Silverman MM, Meyer PM, Sloane F, Raffel M, Pratt DM. The Big Ten Student Suicide Study: a 10year study of suicides on midwestern university campuses. Suicide $\&$ life-threatening behavior. 1997; 27(3):285-303. [PubMed: 9357084]

Spitzer RL, Kroenke K, Williams JB. Validation and utility of a self-report version of PRIME-MD: the PHQ primary care study. Primary Care Evaluation of Mental Disorders. Patient Health Questionnaire. JAMA. 1999; 282(18):1737-1744. [PubMed: 10568646]

Spitzer RL, Williams JBW, Kroenke K, Hornyak R, McMurray J. Validity and utility of the PRIMEMD patient health questionnaire in assessment of 3000 obstetric-gynecologic patients: the PRIMEMD Patient Health Questionnaire Obstetrics-Gynecology Study. American journal of obstetrics and gynecology. 2000; 183(3):759-769. [PubMed: 10992206]

Stoep AV, McCauley E, Flynn C, Stone A. Thoughts of death and suicide in early adolescence. Suicide \& life-threatening behavior. 2009; 39(6):599-613. [PubMed: 20121323]

Team, R.D.C. R: A language and environment for statistical computing. R Foundation for Statistical Computing; Vienna, Austria: 2008.

Thompson M, Kuruwita C, Foster EM. Transitions in suicide risk in a nationally representative sample of adolescents. The Journal of adolescent health : official publication of the Society for Adolescent Medicine. 2009; 44(5):458-463. [PubMed: 19380093] 


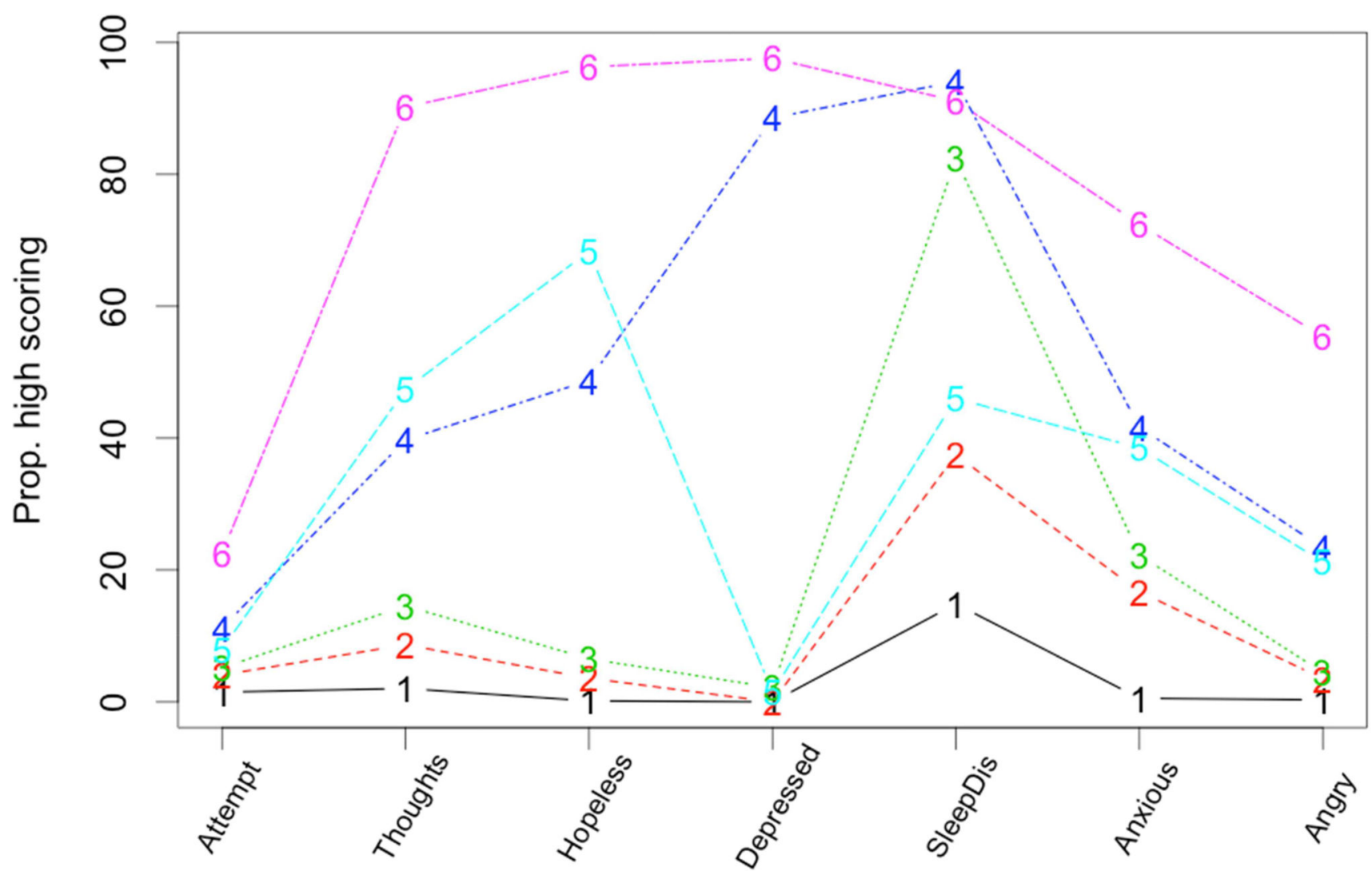

Figure 1.

Profile plot of the 6 classes showing the proportion of each class endorsing the following.

Attempt: reported history of suicide attempt. Thoughts: recent thoughts of suicide.

Hopeless: hopeless a lot or most of the time. Depressed: moderately severe or severe depression on the PHQ9. Disrupted: disrupted sleep a lot or most of the time in past 2 weeks. Anxious: intensely anxious/panicked a lot or most of the time in past 4 weeks.

Angry: intensely angry a lot or most of the time in past 4 weeks. 
Relationship between PHQ8 score and thoughts of suicide

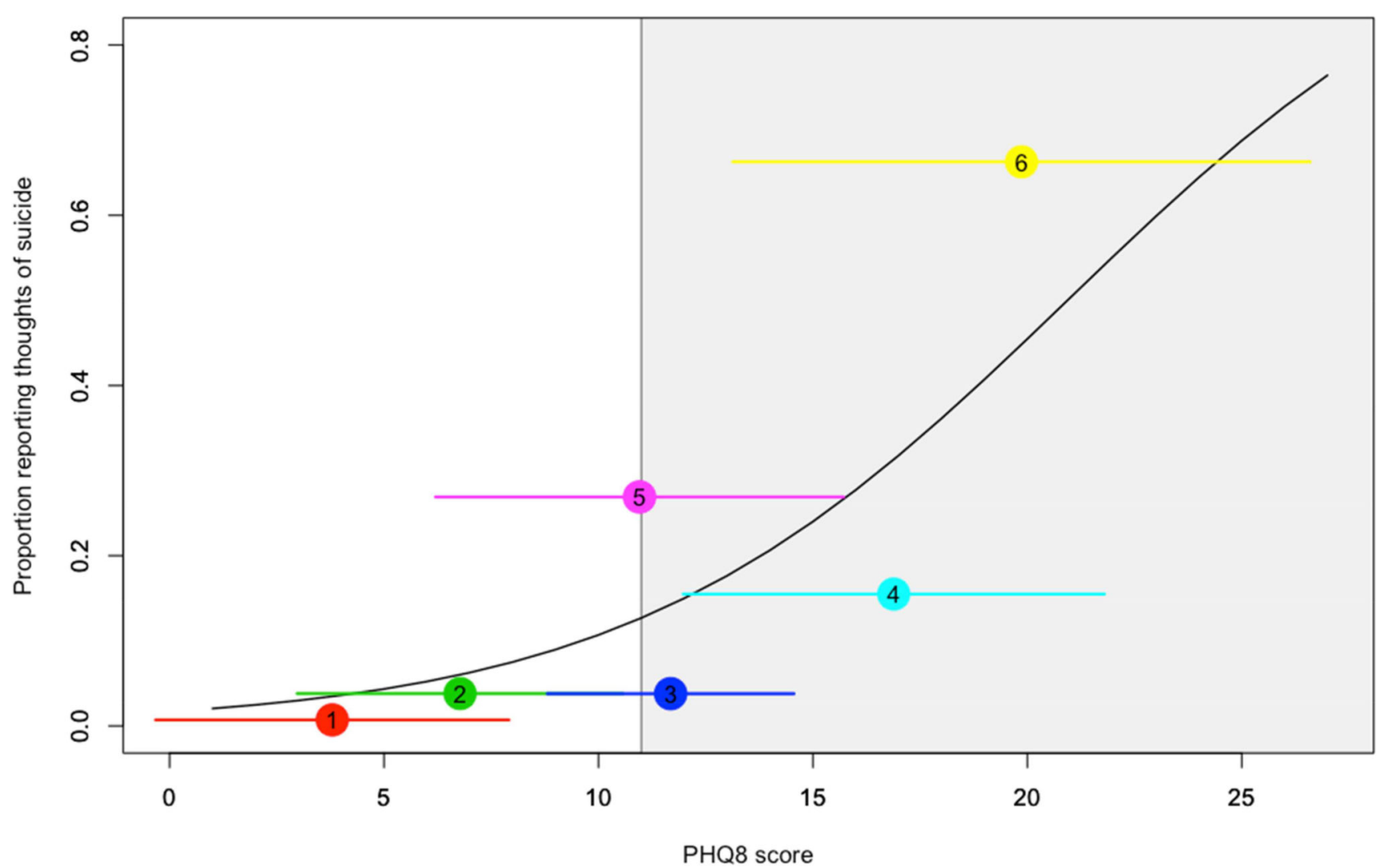

Figure 2.

Expected and observed proportion of respondents reporting thoughts of suicide in each class among the undergraduates. 


\section{Table 1}

Comparison of demographic characteristics and survey responses of undergraduate and graduate students. All p-values were adjusted for clustering by institution.

\begin{tabular}{|c|c|c|c|}
\hline & Undergraduate Students & Graduate/Professional Students & P-value \\
\hline $\mathbf{N}$ & 5654 & 1138 & \\
\hline \multirow[t]{3}{*}{ Age } & Median: 20 & Median: 26 & $<0.0001$ \\
\hline & Mean: 21.6 & Mean: 27.11 & \\
\hline & Range: 17-64 & Range: $18-70$ & \\
\hline \multirow[t]{4}{*}{ Gender } & Female: $3723(65.7 \%)$ & Female: $655(57.6 \%)$ & 0.594 \\
\hline & Male: $1763(31.1 \%)$ & Male: $452(39.7 \%)$ & \\
\hline & Other: $17(0.3 \%)$ & Other: $2(0.2 \%)$ & \\
\hline & Did not answer: $151(2.7 \%)$ & Did not answer: $29(2.5 \%)$ & \\
\hline \multirow[t]{5}{*}{ Difficulty functioning in past 2 weeks } & Not difficult: 1179 (20.8\%) & Not difficult: 268 (23.6\%) & $0.7059^{*}$ \\
\hline & Somewhat difficult: 3034 (53.6\%) & Somewhat difficult: $633(55.6 \%)$ & \\
\hline & Very difficult: $1050(18.5 \%)$ & Very difficult: $178(15.6 \%)$ & \\
\hline & Extremely difficult: $364(6.4 \%)$ & Extremely difficult: 51 (4.5\%) & \\
\hline & Did not answer: $27(0.5 \%)$ & Did not answer: $8(0.7 \%)$ & \\
\hline \multirow[t]{4}{*}{ Categorical PHQ9 score } & None: $59(1 \%)$ & None: $12(1.1 \%)$ & $0.7292^{*}$ \\
\hline & Minimal or mild: 2816 (49.7\%) & Minimal or mild: $656(57.6 \%)$ & \\
\hline & Moderate: $1439(25.4 \%)$ & Moderate: $299(26.3 \%)$ & \\
\hline & Moderately severe or severe: $1340(23.7 \%)$ & Moderately severe or severe: $171(15 \%)$ & \\
\hline \multirow[t]{3}{*}{ Thoughts of suicide in past 2 weeks } & No: $4839(85.6 \%)$ & No: $1023(89.9 \%)$ & $0.8270^{*}$ \\
\hline & Yes: $807(14.3 \%)$ & Yes: $114(10.0 \%)$ & \\
\hline & Did not answer: $8(0.1 \%)$ & Did not answer: $1(0.1 \%)$ & \\
\hline \multirow[t]{3}{*}{ Reported history of suicide attempt } & No: $5244(92.7 \%)$ & No: $1082(95.1 \%)$ & $0.277^{*}$ \\
\hline & Yes: $404(7.1 \%)$ & Yes: $56(4.9 \%)$ & \\
\hline & Did not answer: $6(0.1 \%)$ & Did not answer: $0(0 \%)$ & \\
\hline
\end{tabular}


로을

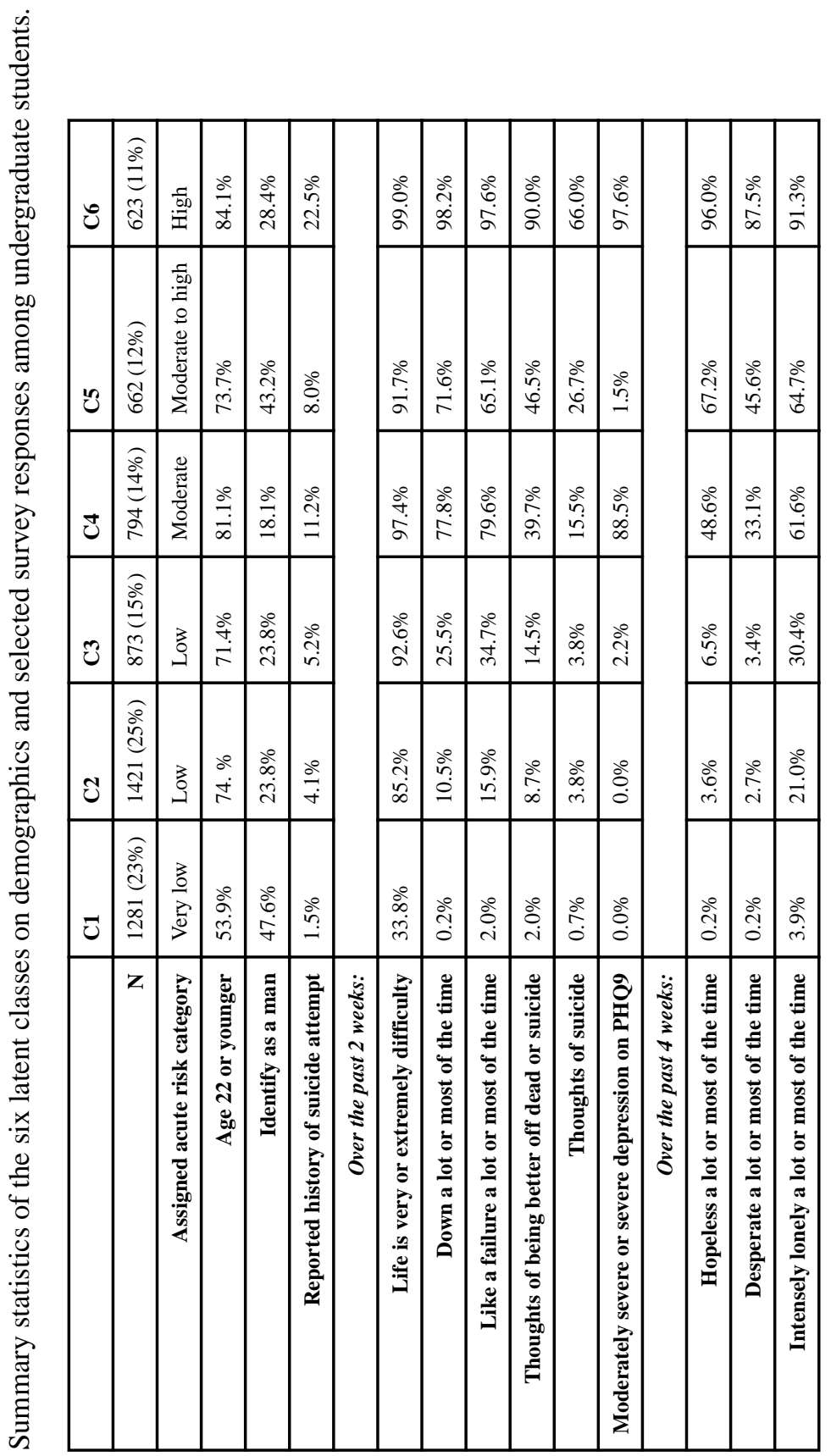

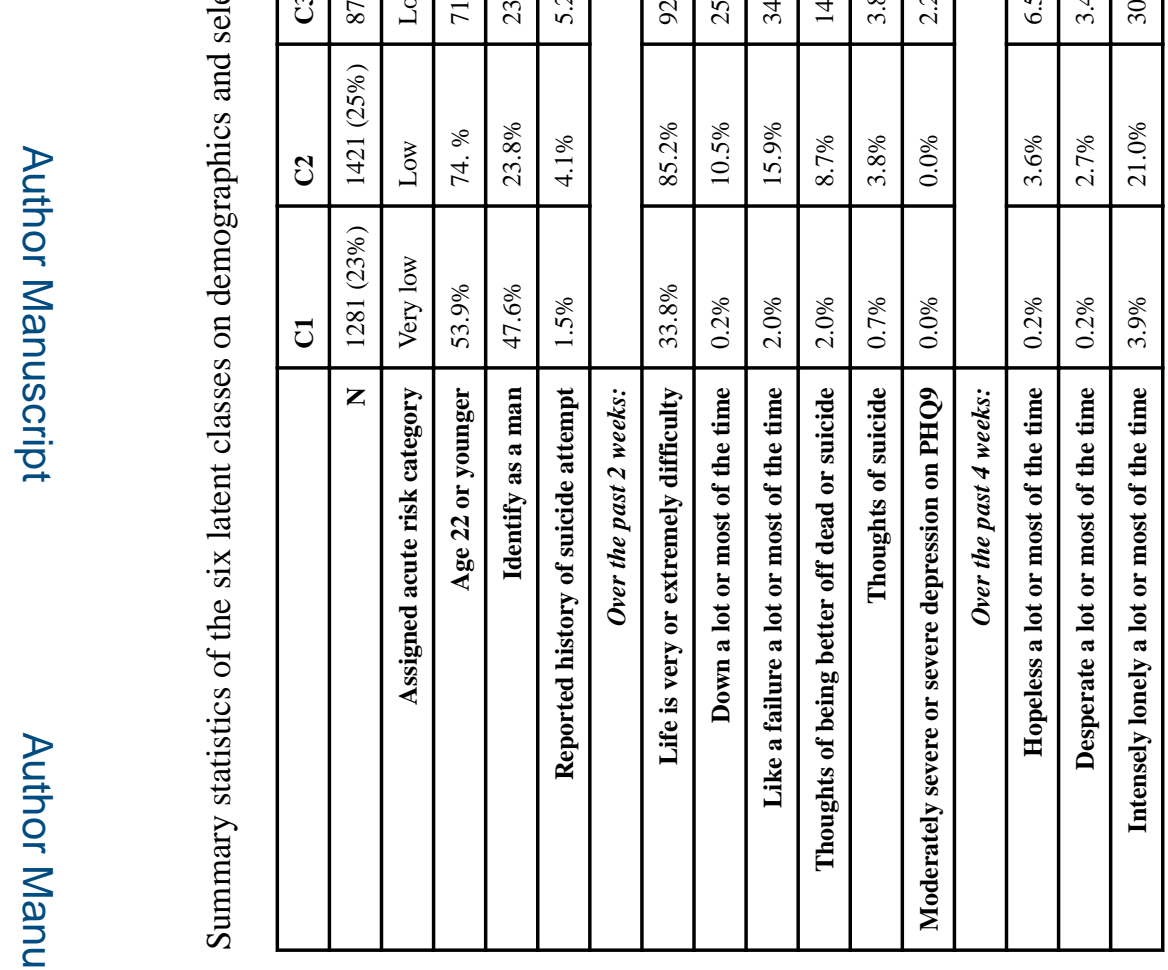

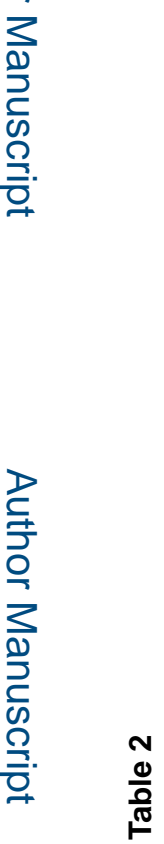

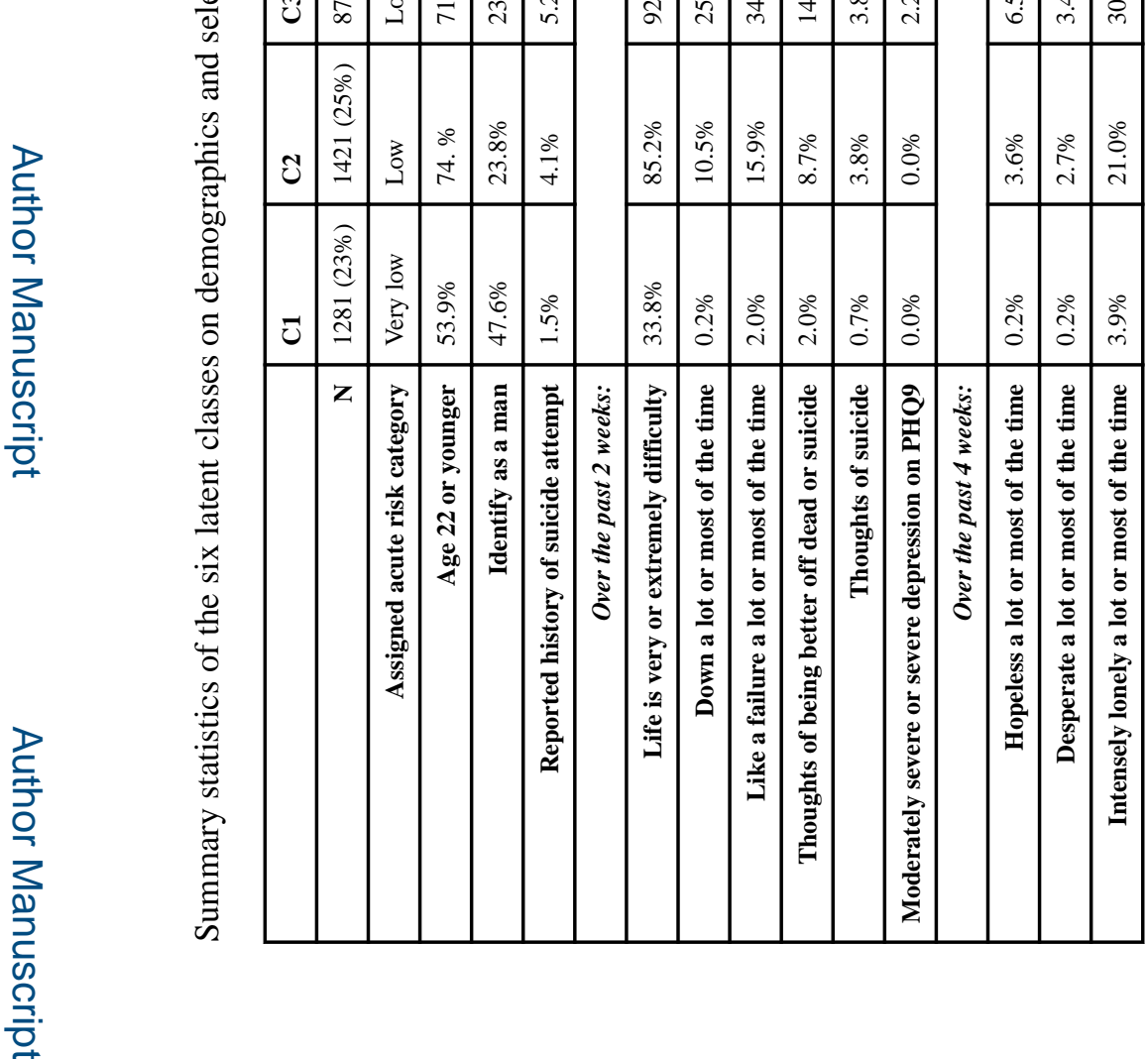

J Psychiatr Res. Author manuscript; available in PMC 2018 December 01. 


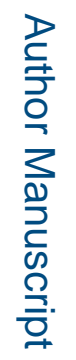



J Psychiatr Res. Author manuscript; available in PMC 2018 December 01. 